\title{
Erratum
}

\section{Erratum: Yakson touch as a part of early intervention in the Neonatal Intensive Care Unit: A systematic narrative review}

In the article, "Yakson touch as a part of early intervention in the Neonatal Intensive Care Unit: A systematic narrative review", which appeared in the pages 349-352, Issue 6, Vol. 20 of Indian Journal of Critical Care Medicine, ${ }^{[1]}$ the fourth author name is incorrectly written as "Vencita Priyanka Aranka" instead of "Vencita Priyanka Aranha".

Additionally, in the "How to cite this article" section the fourth author name is incorrectly written as "Aranka $\mathrm{VP}^{\prime \prime}$ instead of "Aranha VP".

These have now been corrected and reposted online.

\section{Reference}

1. Parashar P, Samuel AJ, Bansal A, Aranha VP. Yakson touch as a part of early intervention in the Neonatal Intensive Care Unit: A systematic narrative review. Indian J Crit Care Med 2016; 20:349-52.

DOI: $10.4103 / 0972-5229.186271$ 